\title{
2D-PAGE analysis of the soluble proteins of the tropical liver fluke, Fasciola gigantica and biliary amphistome, Gigantocotyle explanatum, concurrently infecting Bubalus bubalis
}

\author{
Yasir A. Khan • Mohd Abdul Hannan Khan • \\ S. M. A. Abidi
}

Received: 31 March 2014 / Accepted: 13 October 2014/Published online: 30 October 2014

(C) Indian Society for Parasitology 2014

\begin{abstract}
The digenetic trematodes, Fasciola gigantica and Gigantocotyle explanatum, belonging to the family Fasciolidae and Paramphistomidae respectively, have been often found to concurrently infect the liver of Indian water buffalo Bubalus bubalis, causing serious pathological damage to the vital organ, incurring huge economic losses. In the present study the soluble gene products of both $F$. gigantica and $G$. explanatum were analyzed by 2 dimensional polyacrylamide gel electrophoresis. The soluble proteomic profile revealed considerable similarity as well as differences in the size, distribution pattern, total number, the isoelectric point $(\mathrm{pI})$ and molecular weight $\left(\mathrm{M}_{\mathrm{r}}\right)$ of the resolved polypeptide spots. The maximum number of polypeptide spots with a molecular weight range of $>10$ to $160 \mathrm{kDa}$ were recorded with a $\mathrm{p} I$ range of 7-9 followed by $\mathrm{p} I$ range of 5-7, 9-10 and 3-5 in both the parasites. However, considerable variation was recorded in the $M_{r}$ of the polypeptides belonging to each $\mathrm{p} I$ range. The genetic heterogeneity could be an obvious contributing factor for such differences but some polypeptides appeared to be conserved in the two species. The molecular similarities and the habitat preference by these worms may be a consequence of microenvironmental cues that guide these flukes to reach their habitat through different routes and establish a successful host-parasite relationship.
\end{abstract}

Keywords Digenetic trematodes - 2D PAGE . Concurrent infection $\cdot$ Bubalus bubalis

Y. A. Khan · M. A. H. Khan · S. M. A. Abidi $(\bowtie)$

Section of Parasitology, Department of Zoology, Aligarh

Muslim University, Aligarh 202 002, India

e-mail: abbasabidi92@hotmail.com

\section{Introduction}

Fasciola gigantica and Gigantocotyle explanatum are the common endoparasite of Indian water buffalo, Bubalus bubalis, with the abattoir prevalence of 31.14 and $80 \%$ infection, respectively, in north India (Garg et al. 2009; Ambu 1978; Nizami et al. 1991) and cause huge economic losses (Anon 2011-2012). F. gigantica and F. hepatica alone are responsible for multimillion USD economic losses worldwide (Morphew et al. 2011), whereas no data is available on the epidemiology and worldwide economic losses due to $G$. explanatum. The concurrent infection of these trematodes has often been recorded (Fig. 1) in the buffaloes slaughtered at the local abattoir.

F. gigantica, commonly known as tropical liver fluke, infects cattle, buffalo, sheep, goat and humans (Hopkins 1992; Rim et al.1994). It has a complex life cycle and various environmental cues influence the larval developmental process (Standen 1995). The G. explanatum is an amphistome parasite which commonly infects the bile duct of Indian water buffalo. The most amazing fact is that both these flukes exhibit strict preference for liver as their final abode but follow a totally different migratory route to reach final destination. The newly excysted juvenile (NEJ) of Fasciola secrete proteases like Cathepsins (Dalton and Heffernan 1989; Smith et al. 1993), penetrate through the intestinal wall and come out into the peritoneal cavity and move towards liver, burrow into the liver parenchyma leaving foot prints behind in the form of fibrotic tunnels and reach permanent location i.e. bile ducts. Whereas after excystation within the duodenum the NEJs of $G$. explanatum show backward migration from intestinal lumen through the bile duct opening in duodenum and reach the upper region of the bile duct where they firmly attach to the epithelium leaving a hard knob like tissue plug at the site of 


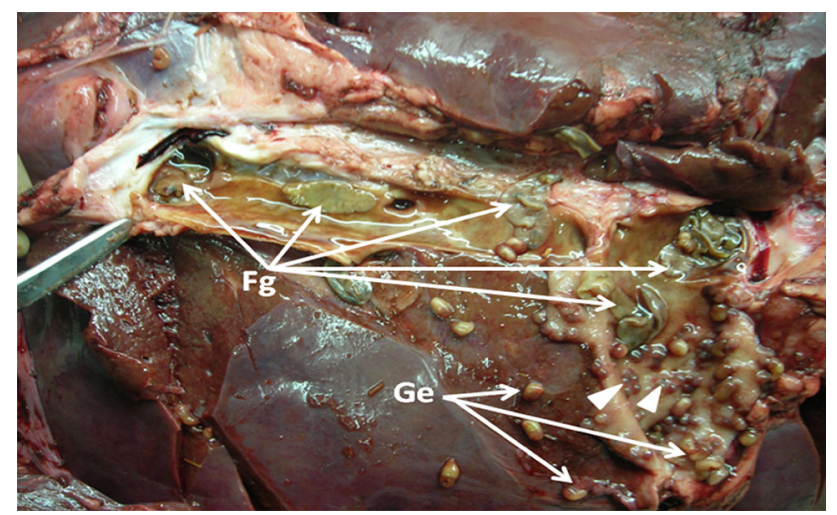

Fig. 1 Concurrently infected liver of Indian water buffalo with Fasciola gigantica and Gigantocotyle explanatum. Leaf like parasites are the $F$. gigantica $(\mathrm{Fg})$ and bulb like G. explanatum $(\mathrm{Ge})$ (shown by arrow head)

attachment (Fig. 1, arrow head). It has been emphasized that biologically important proteins such as cathepsin L, glutathione s-transferases etc. which involved in migration and establishment are both expressed and secreted by these parasites. Further, an understanding basic biology underpinning target expression within parasite population is a pre-requisite for vaccine discovery and development (Morphew et al. 2011).

In the present study a preliminary attempt has been made to generate a 2D- electrophoretic map of the soluble somatic proteins in order to understand basic similarities and differences in the polypeptide profile of the tropical liver fluke and the biliary amphistomes with a subsequent aim to identify the candidates that may be playing a role in habitat predilection.

\section{Materials and methods}

Parasite collection

Adult $F$. gigantica and G. explanatum were collected separately from the same infected liver of the freshly slaughtered Indian water buffalo at the local abattoir, brought to laboratory and washed with Hanks's Balanced Salt Solution (HBSS), pH 7, premaintained at $38{ }^{\circ} \mathrm{C}$, and supplemented with $0.5 \%$ antibiotic/antimycotic solution (Hi media). Worms were incubated for one hour at $38{ }^{\circ} \mathrm{C}$ in Phosphate buffered saline (PBS) $\mathrm{pH}$ 7.4 , for regurgitation of gut contents, thereafter rinsed in fresh medium and then stored at $-80{ }^{\circ} \mathrm{C}$ until used. The parasites were collected from concurrently infected three buffaloes.

\section{Preparation of somatic extract}

The parasite homogenates $(10 \%$, w/v) were separately prepared in a glass tissue homogenizer by taking $1 \mathrm{gm}$ of each parasite in $10 \mathrm{ml}$ of $50 \mathrm{mM}$ tris- $\mathrm{HCl}, \mathrm{pH} 8.0$, on ice and then centrifuged at $10,000 \times g$ for $30 \mathrm{~min}$ at $4{ }^{\circ} \mathrm{C}$. The cell free supernatant was then collected and stored at $-80{ }^{\circ} \mathrm{C}$ for subsequent use.

\section{2-dimensional polyacrylamide gel electrophoresis}

The cell free somatic proteins of both the parasites, $F$. gigantica and G. explanatum, were separately precipitated with an equal volume of $10 \%$ trichloroacetic acid prepared in acetone, at $-20{ }^{\circ} \mathrm{C}$ for $3 \mathrm{~h}$. The precipitated protein was centrifuged at $10,000 \times g$ for $20 \mathrm{~min}$ at $4{ }^{\circ} \mathrm{C}$ and washed four times with chilled acetone for 20 min each. Pellets were partly air dried on ice and then solubilized in rehydration sample buffer consisting of $7 \mathrm{M}$ urea, $2 \mathrm{M}$ thiourea, $4 \%$ w/v CHAPS, $66 \mathrm{mM}$ DTT and $0.5 \%$ Biolyte $(\mathrm{pH}$ 3-10) (Bio Rad, USA). The soluble proteins were focused on IPG strips, pI 3-10 (Bio Rad, USA) for a total of $60,000 \mathrm{Vh}$ in Protean IEF Cell (Bio Rad). Prior to focusing the protein concentration was determined by the method of Spector (1978) using bovine serum albumin (BSA) as standard. After focussing, the IPG strips were equilibrated for $15 \mathrm{~min}$ in reducing solution containing $30 \% \mathrm{v} / \mathrm{v}$ glycerol, $6 \mathrm{M}$ urea, $1 \%$ dithiothreitol (DTT), followed by equilibration in alkylating buffer consisting of $30 \% \mathrm{v} / \mathrm{v}$ glycerol, $6 \mathrm{M}$ urea and $4 \%$ iodoacetamide. Afterwards, the IPG strips were transferred onto a linear $10 \%$ SDS-polyacrylamide gel and electrophoresis was performed at a constant voltage of $100 \mathrm{~V}$, gels were silver stained according to the protocol of Blum et al. (1987) and the image was taken on Gel DocXR + system (Bio Rad, USA). The experiment was repeated for five times and a representative gel image has been given in the results.

\section{Results}

The concurrent infection of the tropical liver fluke, $F . g i$ gantica and the biliary amphistome, G. explanatum, has often been recorded during the collection of parasites from the freshly slaughtered Indian water buffalo at the local abattoir (Fig. 1). The intensity of infection as well as parasite density varied, depending upon the different adjoining districts from where the animals were brought. When the soluble proteins of adult $F$. gigantica and $G$. explanatum, were subjected to $2 \mathrm{D}$ electrophoresis, a discrete polypeptide profile of both the worms (Fig. 2a, b), showing characteristic similarities and differences in the polypeptide spot position, total number, molecular weight and isoelectric points was achieved. The apparent molecular weight of the polypeptides was observed in the range of 10 to $>200 \mathrm{kDa}$. The polypeptides were differentially distributed with respect to their $\mathrm{p} I$ values. The maximum 
Fig. 2 2D PAGE profile of

Fasciola gigantica (a) and Gigantocotyle explanatum (b), total somatic proteins [precipitated in $10 \% \mathrm{TCA}$ acetone, (w/v)]. Both the gels have huge dissimilarity in their protein content but the circles shows the major differences in positioning of abundantly expressed proteins

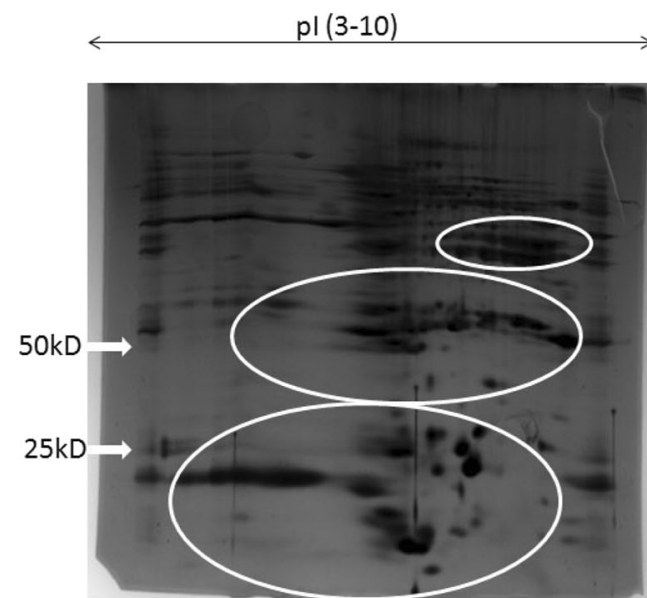

(a)

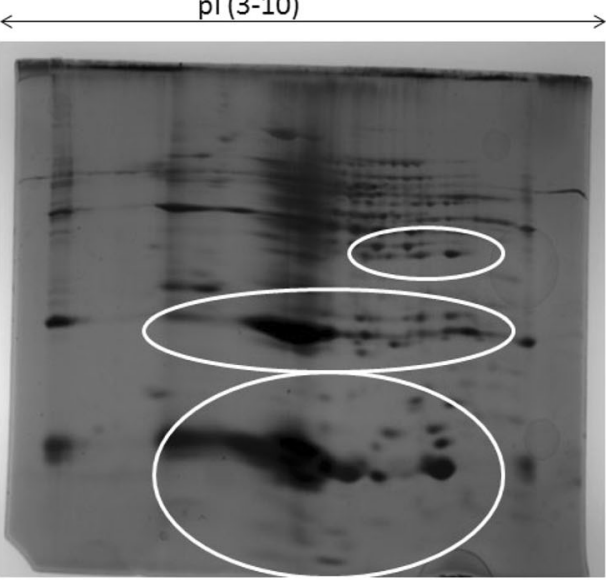

(b) number of the polypeptides in both the species was recorded within the $\mathrm{p} I$ range of 7 to 9 , followed by $\mathrm{p} I$ range of 5-7, 9-10 and 3-5 in both the worms. Significant differences in the number of spots and their size in the range of low molecular weight proteins of both the polypeptide profile was also recorded. It is possible that the generic differences and the micro niche preferences are reflected in the polypeptide profile of these two digenetic trematodes.

\section{Discussion}

The concurrent infection of the tropical liver fluke and the biliary amphistome, $F$. gigantica and the $G$. explanatum respectively, in Indian water buffalo, with their similarities and differences in the polypeptide profile, has drawn our attention to raise a number of fundamental questions related to their basic biology, morphology, physiology, biochemistry, immunology and molecular aspects with particular reference to habitat predilection, virulence potential, migratory behavior and immune evasion.

The critical observations on the behavioral differences and similarities has instilled few questions like: (1) why these worms exhibit strict habitat specificity? (2) What neurological or other stimuli guide them to reach the same site of infection but through completely different migratory route- the $F$. gigantica worms penetrate through the intestinal wall, enter peritoneum, reach liver, where it burrow into the tissue to arrive in the bile ducts, whereas $G$. explanatum takes a normal route through the duodenum to common bile duct to reach liver. Perhaps the answer may lie in identification and characterization of functionally important polypeptides which are important for cellular differentiation and habitat selection.

It is possible that the evolutionarily conserved proteins across phyla might be playing a part in recognizing the similar microenvironmental cues provided by the habitat, but the differences in their polypeptide profile could be a consequence of genetic heterogeneity of these worms. Molecular heterogeneity of the organisms are reflected in their differential gene expression leading to the formation of various gene products which are required for diverse biological functions. Therefore, identification and characterization of polypeptides of these parasites may provide some answers. Our preliminary study shows both qualitative as well as quantitative differences in the $2 \mathrm{D}$ polypeptide profile of the parasite species under study. The protein profile showing pronounced generic differences among the adult amphistomes have been reported in previous studies and it has been suggested that protein electrophoresis can also be used as a powerful tool for biochemical taxonomy (Osikovski et al. 1978; Alam and Nizami 1988; Saifullah et al.2001). The analysis of banding pattern of soluble egg proteins also shows considerable similarities and variations in the molecular weights of a number of closely related trematode species infecting the Indian water buffalo (Saifullah et al.2001) but nothing can be said about their isoelectric points. Using the broad range (pI 3-10) carrier ampholytes the maximum number of soluble proteins of both $F$. gigantica and $G$. explanatum adult worms were focused within the $\mathrm{p} I$ range of 7 to 9 with a molecular weight range of 9.8 to $238 \mathrm{kDa}$ in the present study. The differences were more prominent in the low molecular weight polypeptides as compared to the high molecular weight polypeptides. Such differences may also account for antigenic heterogeneity (Simpson 1986). For better resolution such differences can be further resolved by using narrow range ampholytes and through mass spectrometry (MS/MS). Khan et al. (1990) reported changes in the distribution of macromolecules including proteins in worms showing seasonally modulated reproductive cycle. In such instances application of proteomic approach 
would help in identifying the polypeptides associated with gonadal regression and recrudescence. It has been pointed out that pathology is directly related to the parasite proteins that facilitate establishment of parasite within the host, and also the proteomic and sub proteomic approach to determine relative expression of proteins would help to delineate the candidate molecules for vaccine development (Morphew et al. 2011).

Further studies are, therefore, required not only to delineate the polypeptides associated with the cellular differentiation, habitat selection and virulence potential of the parasites understudy, but also to test their potential as a candidate for diagnosis and the development of a vaccine that could be used for cross protection of infection since Fasciola hepatica excretory secretory antigens have been reported to provide considerably high level of protection to mice against Schistosoma mansoni (Hamed 2006).

Acknowledgments Authors are grateful to the Chairman, Department of Zoology, Aligarh Muslim University for providing the necessary facilities. Thanks are extended to University Grants Commission, New Delhi for financial assistance to YAK. Financial support under the BBSRC UK CIDLID project to SMAA and fellowship to MAHK is also gratefully acknowledged.

\section{References}

Alam SM, Nizami WA (1988) Protein polymorphism of some amphistomes and their host tissue. Acta Vet Hung 36:247-250

Ambu SA (1978) Survey of amphistomes of cattle and buffaloes at the Shah Alam Abattoir, Selangor, Malaysia. Southeast Asian J Trop Med Public Health 9:443-444

Anon (2011-2012) Annual report-Department of Animal Husbandry, Dairying and Fisheries, Ministry of Agriculture, Government of India, pp 1-112 (Gives data on both Fasiolosis and amphistomosis)

Blum H, Beier H, Gross HJ (1987) Improved silver staining of plant proteins, RNA and DNA in polyacrylamide gels. Electrophoresis 8:93-99
Dalton J, Heffernan M (1989) Thiol proteases released in vitro by Fasciola hepatica. Mol Biochem Parasitol 35:161-166

Garg R, Yadev CL, Kumar RR, Banerjee PS, Vatsys S, Godara R (2009) The epidemiology of fasciolosis in ruminants in different geo-climatic regions of north India. Trop Anim Health Prod 41:1695-1700

Hamed MA (2006) Excretory products of Fasciola hepatica worms protects against Schistosoma mansoni infection in mice. Indian J Exp Biol 44:554-561

Hopkins DR (1992) Homing in on helminths. Am J Trop Med Hyg 46:626-634

Khan P, Nizami WA, Ahmad M, Abidi SMA (1990) Biochemical variations in Gigantocotyle explanatum and Gastrothylax crumenifer with respect to their seasonal reproduction. Int $\mathbf{J}$ Parasitol 20:109-117

Morphew RM, Wright HA, LaCourse EM, Porter J, Barrett J, Woods DJ, Brophy PM (2011) Towards delineating functions within the Fasciola secreted cathepsin L protease family by integrating in vivo based sub proteomic phylogenetics. PLoS Neg Trop Dis 5(1):1-16

Nizami WA, Khan P, Abidi SMA (1991) Problems and prospects of buffalo amphistomosis. Parasit Hung 24:69-79

Osikovski E, Kamburov P, Vasilev I (1978) Comparative electrophoretic study of the water-soluble proteins of some representative of genus Paraamphistomum. Khelminthologiye Sofia 6:68-74

Rim HJ, Farag HF, Sornmani S, Cross JH (1994) Food-borne trematodes: ignored or emerging? Parasitol Today 10:207-209

Saifullah MK, Abidi SMA, Nizami WA (2001) Polypeptide profile of in vitro released eggs of some digenetic trematodes. J Vet Parasit 15(1):25-28

Simpson AJG (1986) The influence of molecular heterogeneity in helminth identification, protective immunity and Immunodiagnosis. In: Parasitology-Quo Vadit? Proceedings of the sixth int cong parasitol, Brisbane, Australia

Smith AM, Dowd AJ, Heffernan M, Robertson CD, Dalton JP (1993) Fasciola hepatica: a secreted cathepsin L-like proteinase cleaves host immunoglobulin. Int J Parasitol 23:977-983

Spector T (1978) Refinement of Coommassie blue method of protein quantitation. Anal Biochem 86:142-146

Standen OD (1995) The effect of temperature, light and salinity upon hatching of the ova of Schistosoma mansoni. Trans R Soc Trop Med Hyg 45:225-241 